\title{
Parents Perceived Quality of Life for Children with Cochlear Implants
}

\author{
Mursalin Molla1, Nurvin Jahan Asha², Mohammad Kamrujjaman ${ }^{3}$ \\ ${ }^{1}$ Smiling Children Special School, Dhaka, Bangladesh \\ ${ }^{2}$ Centre for the Rehabilitation of the Paralysed (CRP), Dhaka, Bangladesh \\ ${ }^{3}$ State College of Health Sciences, Dhaka, Bangladesh \\ Email: kamrujjaman10@gmail.com
}

How to cite this paper: Molla, M., Asha, N.J. and Kamrujjaman, M. (2019) Parents Perceived Quality of Life for Children with Cochlear Implants. International Journal of Otolaryngology and Head \& Neck Surgery, 8, 13-24.

https://doi.org/10.4236/ijohns.2019.81003

Received: October 26, 2018

Accepted: December 8, 2018

Published: December 11, 2018

Copyright $\odot 2019$ by authors and Scientific Research Publishing Inc. This work is licensed under the Creative Commons Attribution International License (CC BY 4.0).

http://creativecommons.org/licenses/by/4.0/

(c) (i) Open Access

\begin{abstract}
The purpose of the study is to identify the important aspects of quality of life assessed in children with cochlear implant. Parental Perspective questionnaire with modified in Bangla was used as a data collection tool in this study. Data was collected through face to face interview with 25 parents of children with Cochlear Implant (CI) attended at Bangabandhu Sheikh Mujib Medical University, Dhaka. Among 25 cochlear implant children, the boys (12) and girls (13) were nearly the same. Results indicated that the majority of the children had difficulties with communication with known people $(48.00 \%)$ and before implantation children with CI obtained no benefit at all from hearing aids $(76.00 \%)$. However, the research finding shows that they are largely satisfied with the outcomes from implantation. Improvement of social relationship, family well-being, within the family, educational condition, and self-reliance was satisfactorily reported by the parents. This study would help the clinician, speech pathologist, children and parents to raise awareness about the impact of $\mathrm{CI}$ and its treatment.
\end{abstract}

\section{Keywords}

Quality of Life, Children, Cochlear Implant

\section{Introduction}

Cochlear Implant (CI) is an electronic device that is implanted into the ear surgically to provide a sense of sound to the deaf or patients who have hearing impairment. Cochlear implantation is to facilitate spoken language development. Therefore, oral/auditory methodologies of language learning are typically recommended for deaf children with cochlear implants [1]. Deaf children do not have the same auditory access as their hearing peers; therefore, their speech and 
listening abilities are often limited [2]. In the United States, roughly 38,000 devices have been implanted in children [3]. Many cochlear implant operations have been done to over 150,000 people including both children and adults worldwide [4]. It is noted that $43 \%$ of the subjects implanted before the age of 2 and $16 \%$ of the subjects implanted before 4 years of age achieved speech and language skills equivalent to their normal hearing peers [5]. Children may learn to use the sensations provided by their implants in different ways, so audiometric measures do not tell us directly about the child's use of the implant in everyday life; this is why they are often complemented by measures of language development and educational achievement [6]. Parents, educators, family members, and anyone in contact with implant users should understand cochlear implants as much as possible. Children who were identified with hearing loss by 6 months of age and received early intervention had significantly better speech and language outcomes compared to children whose hearing loss was identified after 6 months of age [7]. Children with hearing loss have explained children's developmental patterns in relation to the various processes associated with language and literacy acquisition (e.g., phonemic awareness, speech perception, fluency, vocabulary, and reading comprehension) in typically developing children [8]. According to Dunn \& Munn (2008), hearing loss is the most common congenital birth defect, affecting 2 - 3 newborns out of every 1000 born in the United States [9] [10]. The World Health Organization (1998) defines quality of life as a broad multi-dimensional paradigm that includes subjective evaluations of gratification or satisfaction with one's life and activities of daily living [11]. This study would be helpful to add knowledge and in making speech and language therapist awareness about the quality of life for parents of children with cochlear implants. Investigator would be professionally taken concerned with the organization for the quality of life for children with cochlear implants. Speech and language therapists can use this information for doing best practice by parents of children communication and concerning functional well-being status of the cochlear implants children.

\section{Description of CI (Cochlear Implant) Device}

Cochlear implants are electronic devices which have both surgically implanted and externally worn parts. This is designed to enhance hearing abilities [12]. It consists of a receiver/stimulator that is surgically implanted under the skin, behind the ear with a magnet and an electrode array. It is implanted into the cochlea and provides direct electrical stimulation to the nerve fibers. The external parts include a microphone, a speech processor, and a transmitting coil that are placed behind the ear [6]. 


\section{Methodology}

Investigator conducted the study in Bangabandhu Sheikh Mujib Medical University (BSMMU), Dhaka \& data was collected from 29th November 2015 to 25th December 2015. The population of the study was parents of children with cochlear implants. Investigator selected 25 children cochlear implant as a participant to conduct this study. It is a judgmental sampling process where individuals are selected purposely based on the study and investigator selected participants according to the aim and objectives of the study [13]. Data was collected from face to face interview with considering the following inclusion \& exclusion criteria.

- Parents of children in both genders aged from 2 to 12 years old.

- Parents of children with the cochlear implant of more than 6 months. Both unilateral and bilateral cochlear implant children.

- Parents of children with CI with other associated disabilities (neurological and behavioral, global development disorder, mild mental impairment, cerebral palsy and diagnosis of meningitis) were excluded.

To assess Quality of Life (QOL), the questionnaire (CCIPP) was used, a specific tool for the pediatric population using CI [14]. The CCIPP consist of 42 general questions divided into seven primary QOL domains: Communication well-being, Social-relationship well-being, Family well-being, General functioning well-being, Self-reliance well-being, Effects of Implantation and education well-being. Parents are asked to tick their responses to the statements on a Likert scale, ranging from strongly agree, agree, neither agree nor disagree, disagree and strongly disagree. Higher scores for the scales and subscales indicate better quality of life [15]. The Investigator used descriptive statistics for data analysis. The percentages of each domain were statistically analyzed using SPSS software. After getting permission from the institute, investigator took an academic permission letter which was approved the principal of BHPI for the study in Bangabandhu Sheikh Mujib Medical University (BSMMU). Permission was also taken from the study in Bangabandhu Sheikh Mujib Medical University (BSMMU) to collect data. After getting permission from the authority of the study at Bangabandhu Sheikh Mujib Medical University (BSMMU), investigator started data collection from the participants.

\section{Results}

Study revealed that among 25 CI children, boys (12) and girls (13) were almost the same. Most of (44\%) the children with CI were 5 - 6 years old. About half of respondents' (52.0\%) professions were house wife. Regarding the educational status of parents, maximum (40\%) completed graduate level as shown in Table 1 .

Analysis of descriptive statistics and Table 2 shows that mean age in years was $7.2( \pm 1.52625)$ followed by mean age at the time of surgery was $3.6360( \pm 1.07776)$ and mean time of using CI was $3.5800( \pm 1.3105)$. 
Table 1. Demographic information of the participants $(n=25)$.

\begin{tabular}{|c|c|c|}
\hline Variables & Number (n) & Percent (\%) \\
\hline \multicolumn{3}{|c|}{ Age of the children } \\
\hline 5 - 6 Years & 11 & 44 \\
\hline 7 - 8 Years & 9 & 36 \\
\hline $9-10$ Years & 5 & 20 \\
\hline \multicolumn{3}{|c|}{ Sex of the children } \\
\hline Boy & 12 & 48 \\
\hline Girl & 13 & 52 \\
\hline \multicolumn{3}{|c|}{ Parents professions } \\
\hline House wife & 13 & 52.0 \\
\hline Teacher & 4 & 16.0 \\
\hline Others & 8 & 32.0 \\
\hline \multicolumn{3}{|c|}{ Educational level of parents } \\
\hline Primary level & 2 & 8 \\
\hline High school & 9 & 36 \\
\hline College & 4 & 16 \\
\hline Graduate & 10 & 40 \\
\hline
\end{tabular}

Table 2. Descriptive statistics of children with CI.

\begin{tabular}{cccccc}
\hline Variables & $\mathrm{n}$ & Minimum & Maximum & Mean & Std. deviation \\
\hline Age in years & 25 & 5.00 & 10.00 & 7.2120 & 1.52625 \\
Age at the time of surgery & 25 & 1.00 & 6.00 & 3.6360 & 1.07776 \\
Time of using cochlear implants & 25 & 2.00 & 6.00 & 3.5800 & 1.31053 \\
\hline
\end{tabular}

Figure 1 shows that the majority of the participants (48.00\%) respond disagree that their children had difficulties with communication with known people. More than half of the participants (64.00\%) answered agree that the quality of their child's speech gives them a cause for concern. About $44.00 \%$ participants was neither agreed nor disagree can on the point of chatting without seeing the face. Most of the parents $(40.00 \%)$ had agreed that they can communicate with children by speaking. Majority of the parents of children with CI (56.00\%) answered agreed on developing their child's spoken language. Maximum child was reported with neither agreed and disagreed by their parents and they had talked and engaged others in conversation.

Figure 2 revealed that about two third of (76\%) responded strongly agreed that before implantation child obtained no benefit at all from hearing aids. More than half of (68.00\%) parents had strongly agreed that the children were totally reliant on implant all the time. About $48.00 \%$ participants agreed that their children knew when s/he (children) wanted to get their attention and another 


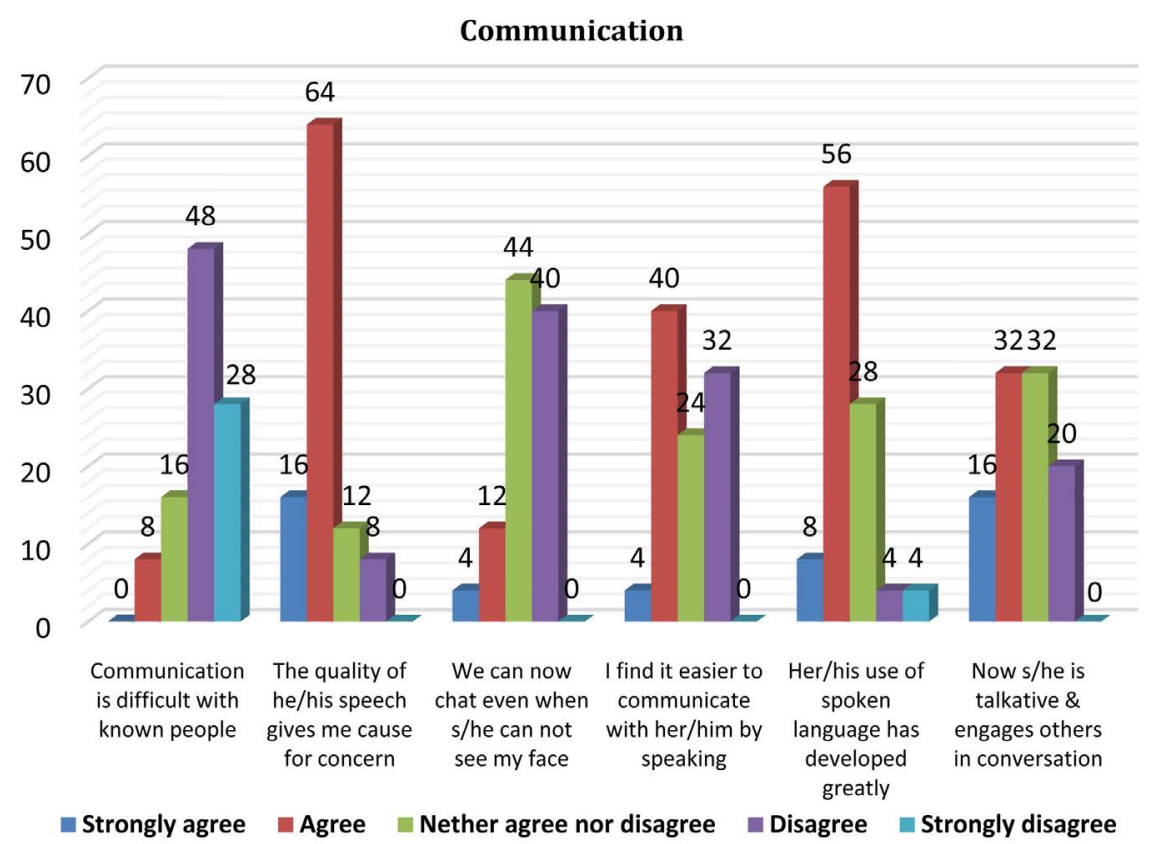

Figure 1. Communication of the children with CI.

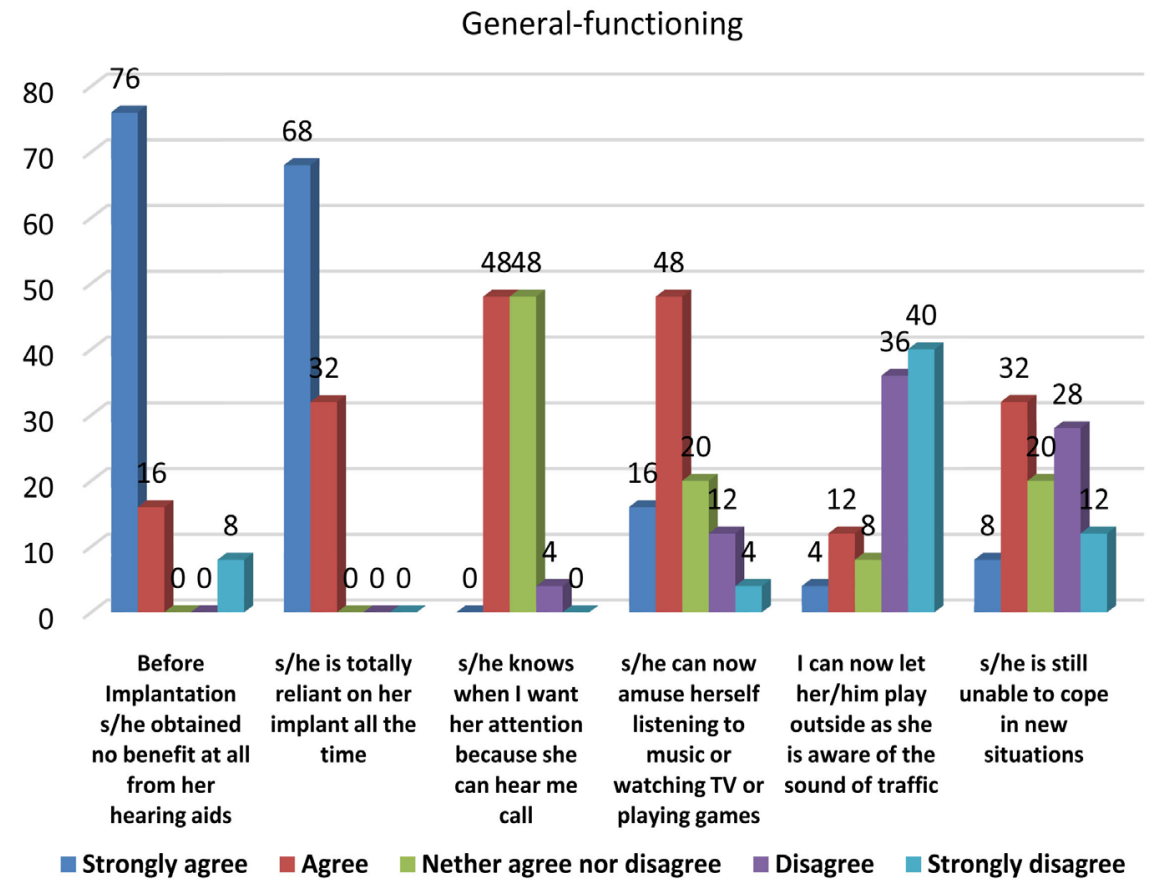

Figure 2. General-functioning of the children with CI.

$48.00 \%$ participants were neither agree nor disagree about this issue. $48.00 \%$ participants responded that their children could amuse themselves by listening to music or watching TV or playing games. $40.00 \%$ participants have strongly disagreed that they had now let her/him play outside as s/he aware of the sound of traffic and another (36.00\%) participants were disagreed. 32.00\% participants answered that $\mathrm{s} / \mathrm{he}$ still unable to cope in new situations. 
Figure 3 demonstrates that more than half of (56.00\%) participants were strongly disagreed that $\mathrm{s} /$ he (children) still shows signs of frustration do something on own. Majority of the parents (72.00\%) agree that they had significant changes of improvement in confidence. More than two third of participants (84.00\%) answered strongly agree that s/he (children) were very dependent on parents before the implantation. $36.00 \%$ participants have disagreed that children independent as most other children of their age and another (36.00\%) participants neither agree nor disagree. Regarding family well-being about $48.00 \%$ have agreed that their children showed signs of frustration in behavior. Majority of the parents $(56.00 \%)$ were agreed that their child's behavior had improved since implantation. $48.00 \%$ participants was agreed that their children became argumentative since getting the implant. $40.00 \%$ participants were strongly disagreed that $\mathrm{s} / \mathrm{he}$ (children) is less frustrated than before the implantation and $36.00 \%$ were disagree. Most of the parents $(84.00 \%)$ were strongly agreed that their children continued to be a happy child. as shown in Figure 4.

Figure 5 shows that Majority of the parents (68.00\%) were strongly disagreed that their children did not have a close relationship with grandparents. $40.00 \%$ participants were agreed that their children were socially isolated before getting implant and $56.00 \%$ sociable within the family. $36.00 \%$ participants responded neither agree nor disagree that the children did not make friends easily outside the family. Most of the participants $(68.00 \%)$ were agreed that their children shared family situations more than before implantation and $64.00 \%$ participants were agreed about the child's relationship with brothers and sisters has been improved.

Analysis of the education and Figure 6 demonstrates that most of the participants $(64.00 \%)$ were strongly agreed that their children were totally reliant on implant at school. $44.00 \%$ participants were agreed that they had a concern

Self-reliance

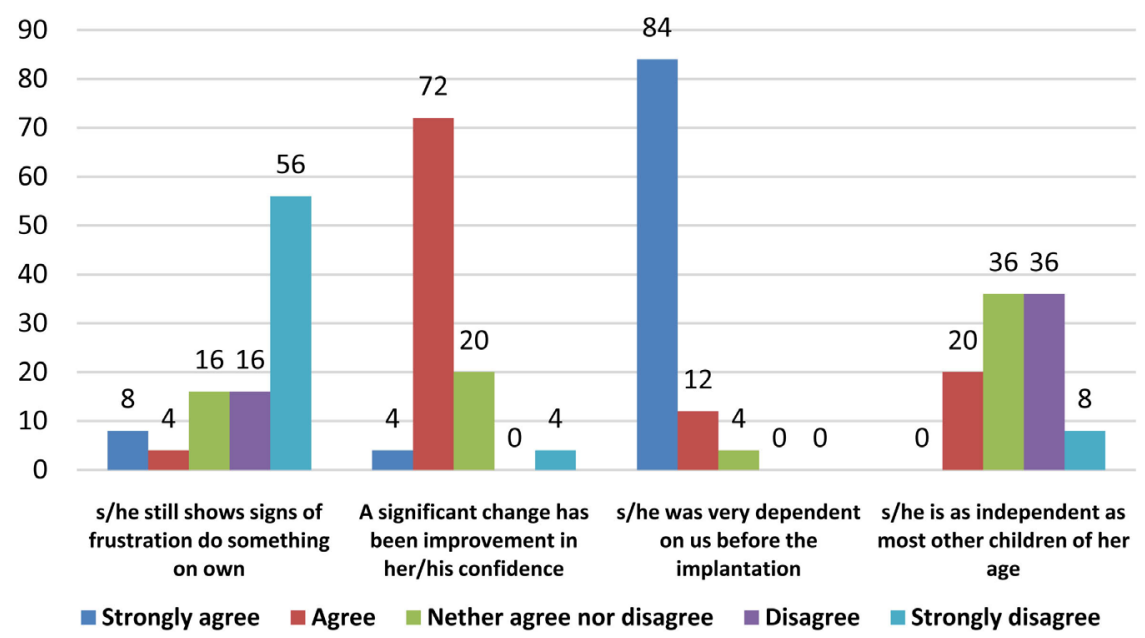

Figure 3. Self-reliance of the children with CI. 


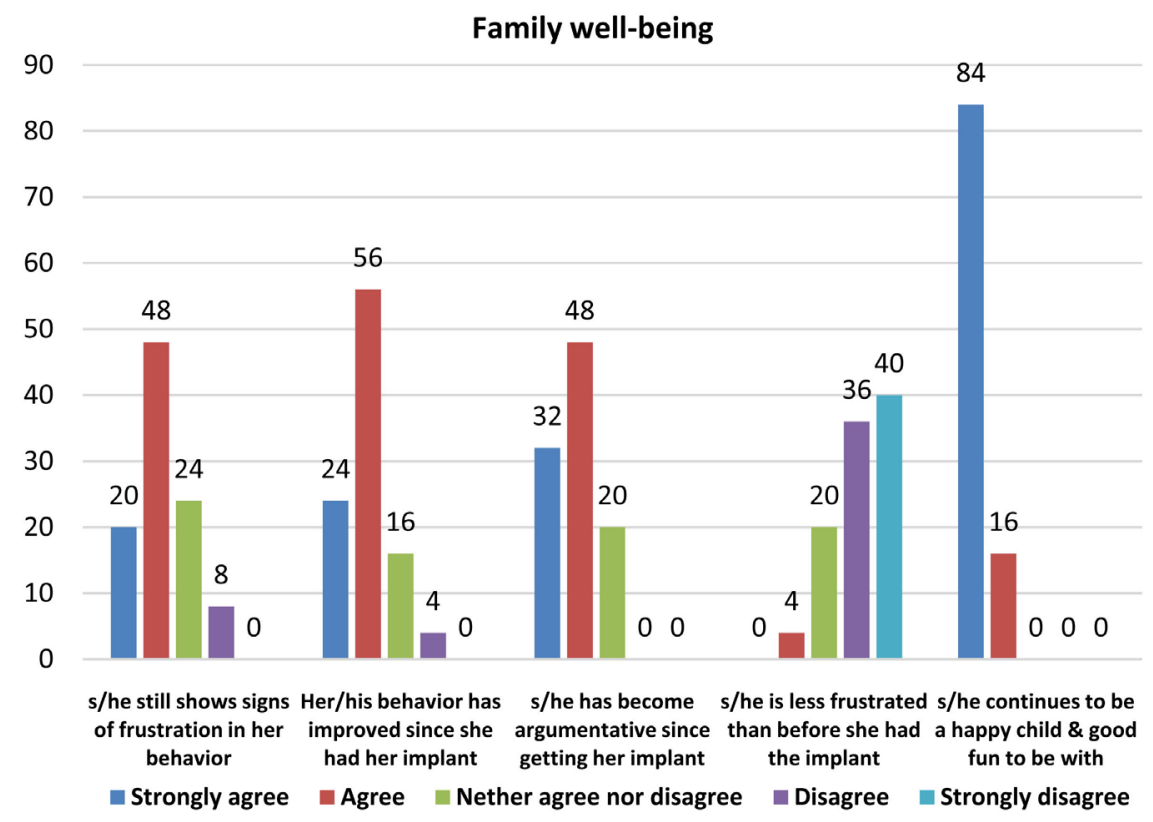

Figure 4. Family well-being of the children with CI.

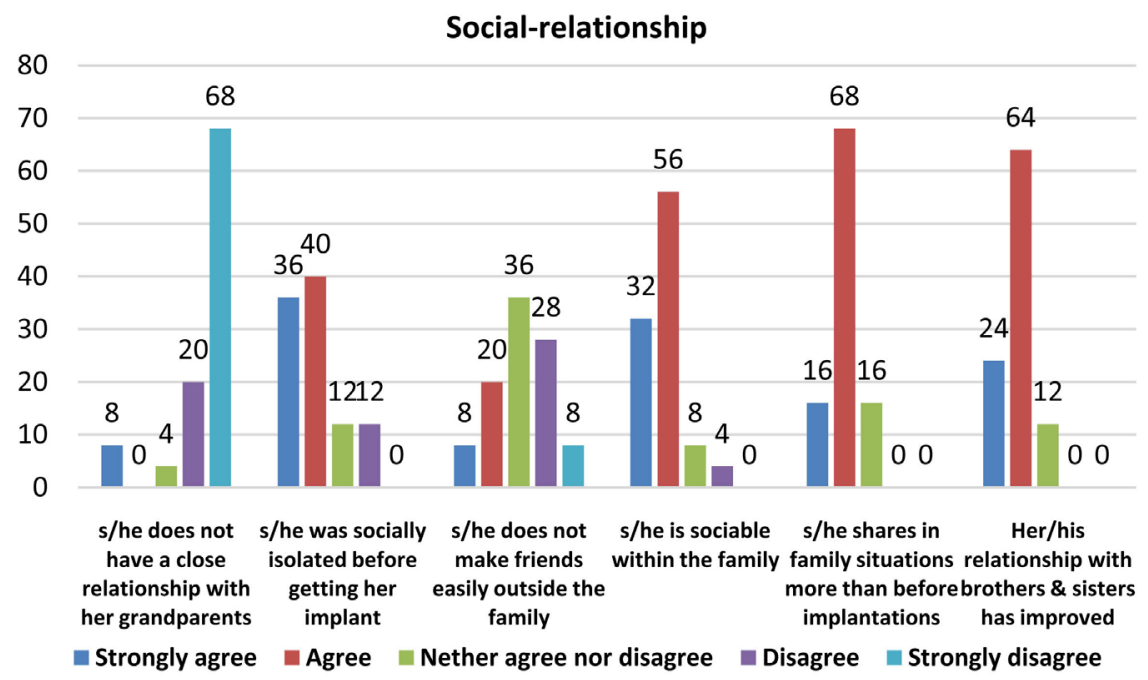

Figure 5. Social-relationship of the children with CI.

about the child's future school placement. $48.00 \%$ participants were agreed that they (parents) should have a choice in the use of sign language at school. $40.00 \%$ participants were happy about their child's progress at school another $36.00 \%$ neither agreed nor disagree. $32.00 \%$ participants were agreed that $\mathrm{s} / \mathrm{he}$ (child's) was unable to cope with mainstream schooling and another $32.00 \%$ have disagreed. $28.00 \%$ participants were agreed that $\mathrm{s} /$ he (children) is keeping up well with children of his/her own age at school and another $28.00 \%$ were disagreed.

Figure 7 demonstrates that $72.00 \%$ participants have strongly disagreed that the immediately after implantation their children ability to communicate was poorer. $48.00 \%$ participants were strongly agreed that their children progress during the first few months seemed very slow and another $40.00 \%$ were agreed. 


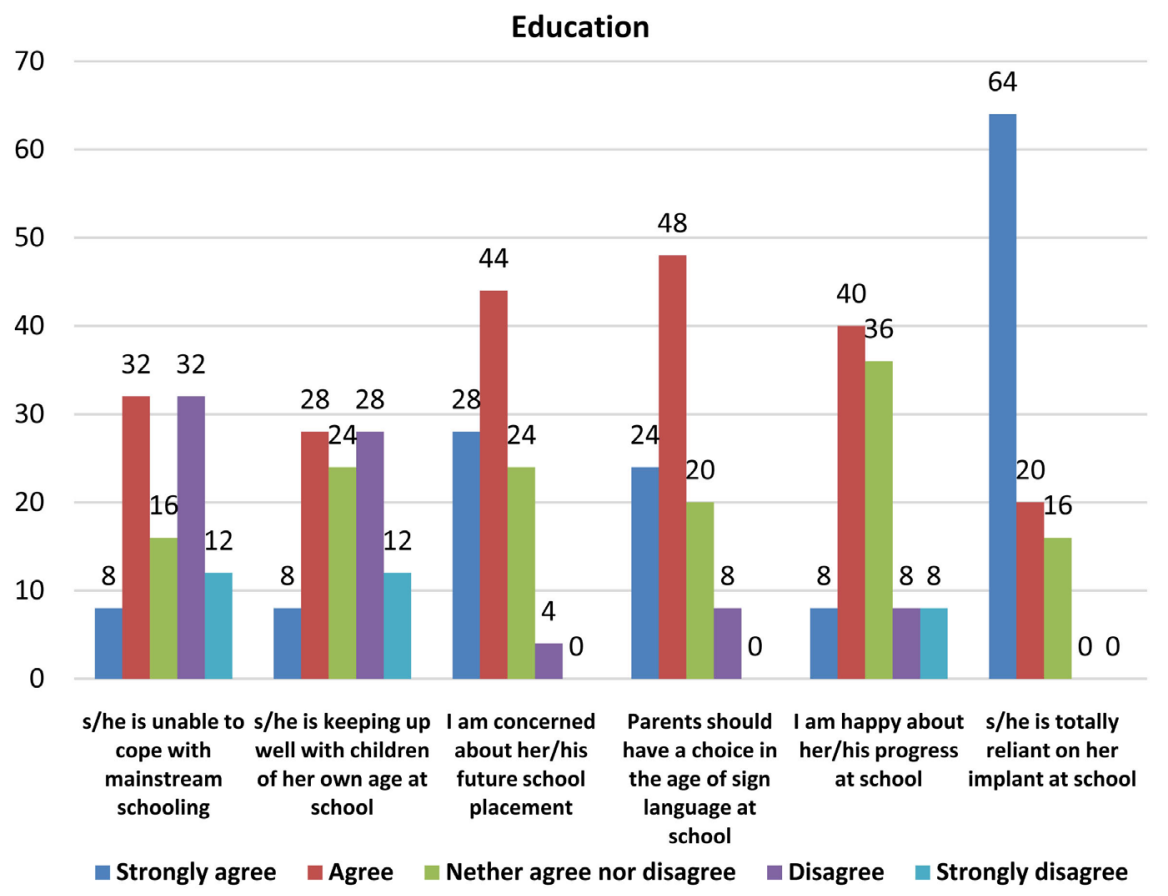

Figure 6. Education of the children with CI.

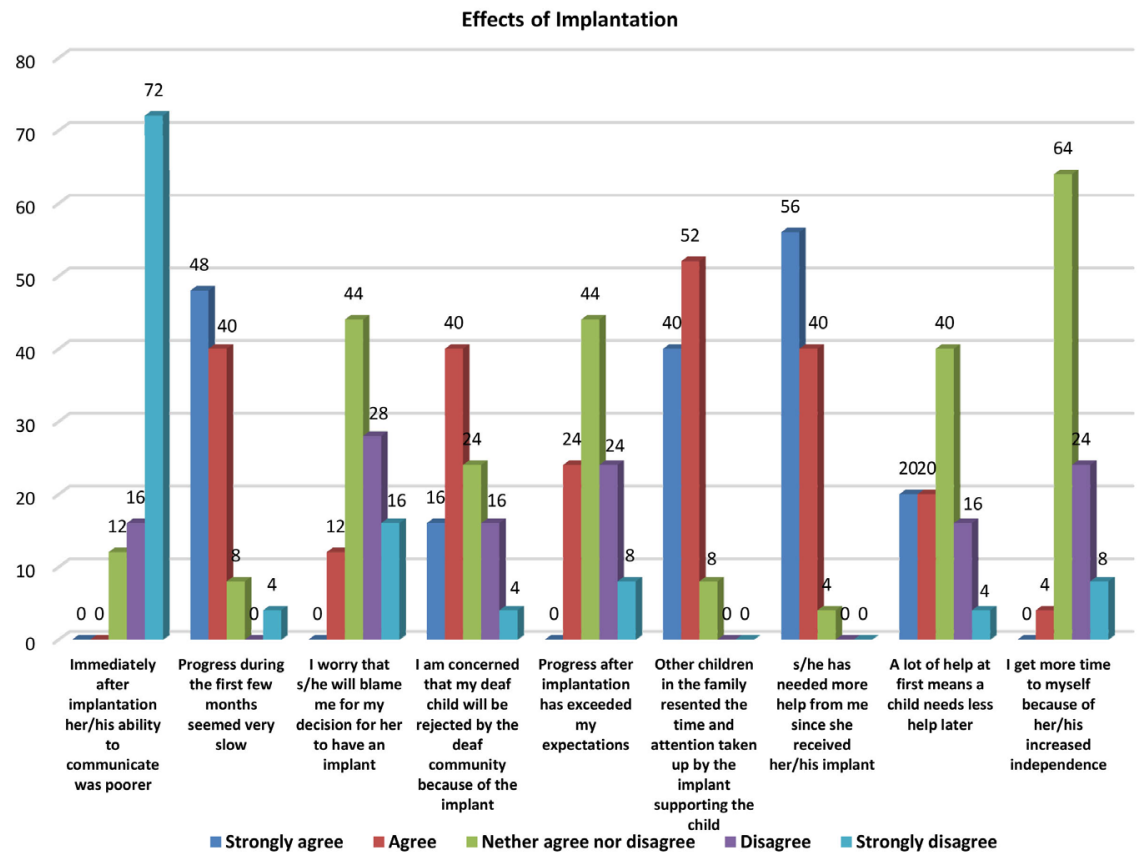

Figure 7. Effects of Implantation among the children with CI.

$56.00 \%$ participants have strongly agreed that their children needed more help from received their child's implant and another $40.00 \%$ were agreed. $44.00 \%$ participants responded neither agree nor disagree that their children blame them for the decision to have been implantation. $44.00 \%$ participants responded were neither agree nor disagree that progress after implantation has exceeded parent's expectations. Majority of the participants (64.00\%) responded were neither agree 
nor disagree that get more time to themselves because of their child's increased independence. $56.00 \%$ participants strongly agreed that their children needed more help from them since received their child's implantation and another $40.00 \% \%$ were agreed. $40.00 \%$ participants were responded neither agree nor disagreed that a lot of help at first means a children needed less help later.

\section{Discussion}

The study revealed on parent's perspective that their children were happy, communicative, and talkative and satisfied with their child's education. The great changes of this study were about spoken language that developed greatly after implantation, which helps to a conversation with others. On the other hand, previous study found that after implantation major outcomes being improvements in communication skills, social relationships and self-reliance [16]. The strongest response of all in this study was that parents reported agreeing that they were able to attract their child's attention by calling them, thus making communication within the family easier [17]. In another study, parents reported that the change to spoken language at home rather than sign language and the child's preference for spoken language as it was the easiest means of communication. In this study, most of the parents (64.00\%) answered agree that the quality of their children speech gave them a cause for concern [18]. Beadle et al. (2005) showed that speech intelligibility is improving even five or ten years after implantation [19]. The present study was carried out after implantation, and therefore it is likely that the quality of the speech of these children has been improved according to parents. Results from this study suggest the majority of the parents $(68.00 \%)$ responded agree that their children were totally reliant on their implant all the time. In a more recent study from interviews with young people with implants was the lack of information about their implant systems [20]. Parents also reported significant changes in confidence as found by Archbold et al. [14]. In this study, the majority of the parents $(72.00 \%)$ agree that they had significant changes of improvement in confidence. Cowan (1997) reported that the cost-benefits of pediatric cochlear implantation are largely dependent on how much rehabilitation the children need after implantation [21]. The parents of profoundly deaf children in the present study strongly agree $(56.00 \%)$ with the statement that their children need more support from them after implantation. A major issue for parents in this study was that their child had become very sociable within the family, sharing family situations, close to grandparents and with improved relationships with their siblings. In this study, most of the parents $(68.00 \%)$ were respond strongly disagree that their children did not have a close relationship with grandparents. The everyday language of the home, of siblings and grandparents after implantation facilitates full participation in family life.18 Education remains a major issue for parents [22]. Although parents report that they are largely happy with their child's education, a significant proportion are concerned about the future and feel their child is not keeping up 
with other children of the same age. The attainment of mainstream schooling has been seen as a measure of the success of cochlear implantation [23]. The majority of the children in the present study were in mainstream education, with $32.00 \%$ parents were agreed and $32.00 \%$ parents disagreed integrated into the mainstream school. With regard to the communication mode in school, over $80 \%$ of parents felt that they should have a say in the use of sign language in school. A study by Watson et al. (2007) interviewing parents about the changes from using sign language to spoken language found that parents wanted to be able to choose communication mode [18]. Christiansen and Leigh (2004) also found in their study that although parents wanted to spoke the language for their child, they also supported the use of sign language before and after implantation [17]. Spencer (2004) also suggests that it may be possible to find a way forward using both sign language and implants and more flexible thinking in considering communication choices would be helpful [6]. In this study, majority of children in the study used signed communication to some extent prior to implantation and changed to using spoken communication over the years following implantation, as became increasingly useful and confirms others that, while parents have the major goal of spoken language for their children, a majority also value the use of sign or signed support at times.

\section{Conclusion}

It is concluded that parents are mostly satisfied with the results from implantation. Their children have developed with a social relationship, family well-being, and communication within the family after implantation. Children may learn to use the sensations provided by their implants in different ways, so audiometric measures do not tell us directly about the child's use of the implant in everyday life. This is why they are often complemented by measures of language development and educational achievement. Children who present with congenital deafness have the potential to reach speech and language outcomes comparable to hearing peers following cochlear implantation. Parents need to be patient as progress takes time, and a number remain concerned about future education, self-reliance, the use of spoken language and feel that outcomes from implantation have not met their expectations. So, speech and language therapist has an important role to play at each of these stages aims to contribute to the assessment, treatment, maximizing and maintenance of abilities relating to general functioning, spoken language and communication.

\section{Limitation of the Study}

This is the first primary study on QOL for children with CI from the perspective of their parents in Bangladesh. So there were some limitations and barriers during conducting the study. The study was done within short period of time and 25 participants or parents were selected to conduct the whole study. It was a small number of participants to conduct a survey to find out QOL for children with 
CIs. Data was collected in Bangla, so there might be a possibility to drop or fall the original meaning of information given by the participants. But the investigator tried to give the original resources in this study. Time and resource were limited that have a great deal of impact on the study. Investigator did not get any financial support to conduct the study and so it was not possible to move and gather more participants or parents from different hospitals around Bangladesh.

\section{Acknowledgements}

The authors would like to thank all the participants and also acknowledge the support provided by the Department of Speech and Language Therapy at Bangladesh Health Professions Institute (BHPI), Savar, Dhaka, Bangladesh.

\section{Conflicts of Interest}

Authors of the article declare that there is no conflict of interest regarding this article.

\section{References}

[1] Goldin-Meadow, S. and Mayberry, R. (2001) How Do Profoundly Deaf Children Learn to Read? Learning Disabilities Research and Practice, 16, 222-229. https://doi.org/10.1111/0938-8982.00022

[2] Geers, A., Nicholas, J. and Sadey A. (2003) Language Skills of Children with Early Cochlear Implantation. Ear and Hearing, 24, 46-58. https://doi.org/10.1097/01.AUD.0000051689.57380.1B

[3] US Food and Drug Administration (FDA) Medical devices: Benefits and Risks of Cochlear Implants. https://www.fda.gov/medicaldevices/productsandmedicalprocedures/implantsandpr osthetics/cochlearimplants/ucm062843.htm

[4] Health Technology Assessment Section (MaHTAS), Medical Development Division and Ministry of Health Malaysia (2009).

[5] Geers, A. (2004) Speech, Language, and Reading Skills after Early Cochlear Implantation. Archives of Otolaryngology: Head and Neck Surgery, 130, 634-638. https://doi.org/10.1001/archotol.130.5.634

[6] Spencer, L., Barker, B. and Tomblin, J.B. (2003) Exploring the Language and Literacy Outcomes of Pediatric Cochlear Implant Users. Ear and Hearing, 24, 236-247. https://doi.org/10.1097/01.AUD.0000069231.72244.94

[7] Yoshinaga-Itano, C. (2003) From Screening to Early Identification and Intervention: Discovering Predictors to Successful Outcomes for Children with Significant Hearing Loss. Journal of Deaf Studies and Deaf Education, 8, 11-30. https://doi.org/10.1093/deafed/8.1.11

[8] Paul, P.V. and Lee, C. (2010) The Qualitative Similarity Hypothesis. American Annals of the Deaf, 154, 456-462. https://doi.org/10.1353/aad.0.0125

[9] Dunn, J. and Munn, P. (1985) Becoming a Family Member: Family Conflict and the Development of Social Understanding in the Second Year. Child Development, 56, 480-492. https://doi.org/10.2307/1129735

[10] Joint Committee on Infant Hearing (2007). http://www.jcih.org/

[11] The World Health Organization (1998) Development and Psychometric Properties. 
Social Science and Medicine, 46, 1569-1585.

[12] National Institute of Deafness and Other Communication Disorders (2009). https://www.nih.gov/about-nih/what-we-do/nih-almanac/national-institute-deafnes s-other-communication-disorders-nided

[13] DePoy, E. and Gitlin, L.N (1998) Introduction to Research: Understanding and Applying Multiple Strategies. 2nd Edition, National Library of Australia. https://trove.nla.gov.au/work/8517171

[14] Archbold, S., Lutman, M., Gregory, S., et al. (2002) Parents and Their Deaf Child: Three Years after Cochlear Implantation. Deafness and Education International, 4, 12-40. https://doi.org/10.1179/146431502790560962

[15] Webster, K., Cella, D. and Yost, K. (2003) The Functional Assessment of Chronic Illness Therapy (FACIT) Measurement System: Properties, Applications, and Interpretation. Health and Quality of Life Outcomes, 1, 79. https://doi.org/10.1186/1477-7525-1-79

[16] Incesulu, A., Vural, M. and Erkam, U. (2003) Children with Cochlear Implants: Parental Perspective. Otology \& Neurotology, 24, 605-611.

https://doi.org/10.1097/00129492-200307000-00013

[17] Christiansen, B. and Leigh, W. (2004) Children with Cochlear Implants: Changing Parent and Deaf Community Perspectives. Archives Otolaryngology-Head \& Neck, 130, 673-677. https://doi.org/10.1001/archotol.130.5.673

[18] Watson, M., Hardie, T., Archbold, M., et al. (2007) Parents' Views on Changing Communication after Cochlear Implantation. Journal of Deaf Studies and Deaf Educations, 13, 104-116. https://doi.org/10.1093/deafed/enm036

[19] Beadle, R., McKinley, J., Nikolopoulos, P., Brough, J., et al. (2005) Long-Term Functional Outcomes and Academic Occupational Status in Implanted Children after 10 to 14 Years of Cochlear Implant Use. Otology \& Neurotology, 26, 1152-1160. https://doi.org/10.1097/01.mao.0000180483.16619.8f

[20] Wheeler, A., Archbold, M., Gregory, S., et al. (2007) Cochlear Implants: The Young People's Perspective. Journal of Deaf Studies and Deaf Education, 12, 303-316. https://doi.org/10.1093/deafed/enm018

[21] Cowan, R.S.C. (1997) Socio-Economic and Educational and Management Issues. Cochlear Implantation for Infants and Children, Singular Publishing Group, Inc., San Diego, London, 223-240.

[22] Sach, T. and Whynes, D. (2005) Pediatric Cochlear Implantation: The Views of Parents. International Journal of Audiology, 44, 400-407. https://doi.org/10.1080/14992020500146500

[23] Francis, W., Koch, E., Wyatt, R., et al. (1999) Trends in Educational Placement and Cost-Benefit Considerations in Children with Cochlear Implants. Archives of Otolaryngology and Head and Neck Surgery, 125, 499-505.

https://doi.org/10.1001/archotol.125.5.499 